\title{
O gênero Halimeda (Bryopsidales, Chlorophyta) no litoral do estado da Bahia, Brasil
}

\section{Gabriel do Nascimento Santos* \& José Marcos de Castro Nunes ${ }^{a}$}

Programa de Pós Graduação em Botânica, Departamento de Ciências Biológicas, Universidade Estadual de Feira de Santana, Feira de Santana, Bahia, Brasil.

Laboratório de Algas Marinhas, Departamento de Botânica, Instituto de Biologia, Universidade Federal da Bahia, Salvador, Bahia, Brasil.

\begin{abstract}
Resumo - Halimeda está entre os gêneros mais abundantes nos recifes tropicais e, devido à capacidade de biomineralização de carbonato de cálcio, é importante no sequestro de carbono, construção e sedimentação dos recifes organogênicos e formação dos sedimentos superficiais marinhos. O litoral da Bahia, o mais extenso do Brasil, carece de estudos detalhados sobre o gênero, a maioria deles limitada a inventários florísticos. Este trabalho apresenta a flora de Halimeda do litoral baiano com base no material depositados nos principais herbários brasileiros e em coletas realizadas entre os anos de 2012 e 2013. São reconhecidas sete espécies, apresentada chave de identificação, além de descrições para o gênero e as espécies, ilustrações, comentários taxonômicos e mapas de distribuição das espécies no litoral da Bahia.

Palavras-chave adicionais: algas calcárias, biodiversidade, Halimedaceae, Nordeste, taxonomia.
\end{abstract}

\begin{abstract}
The genus Halimeda (Bryopsidales, Chlorophyta) on the coast of the state of Bahia, Brazil) - Halimeda is among the most abundant genus in tropical reefs and, due to the ability to biomineralization of calcium carbonate, it is important in carbon sequestration, construction and sedimentation of organogenic formation of reefs and marine superficial sediments. The coast of Bahia, the most extensive of Brazil, lacks detailed studies on the genus, most of which are limited to floristic inventories. This paper presents the flora of Halimeda from Bahia coast based on material deposited in the main Brazilian herbaria and from sampling in Bahia coast between the years 2012 and 2013. Seven species are recognized and an identification key along with descriptions of the genus and species, illustrations, taxonomic notes and distribution maps for species in Bahia are provided.
\end{abstract}

Additional keywords: biodiversity, calcareous algae, Halimedaceae, Northeast Brazil, taxonomy

O gênero Halimeda J.V. Lamour. está entre os mais abundantes em número de espécies nos recifes tropicais (Hillis-Colinvaux 1986a) e, por sua capacidade de biomineralização de carbonato de cálcio, são importantes no sequestro de carbono, fundamentais para o balanço das concentrações do gás carbônico atmosférico (Ries 2005), além de contribuírem na construção e sedimentação dos recifes organogênicos (Hillis-Colinvaux 1986b; Amorin et al. 2006; DeWreede, 2006), bem como na formação dos sedimentos superficiais marinhos (Drew 1983). Como os demais representantes da ordem Bryopsidales, são ubíquos e ecologicamente importantes em ecossistemas marinhos tropicais (Clifton \& Clifton 1999), sendo particularmente abundantes na zona fótica.

Os representantes de Halimeda são caracterizados por um talo calcificado, ramificado em vários planos, dividido em segmentos por uma constrição denominada região nodal, tendo hábito ereto ou prostrado, fixados ao substrato por uma ampla gama de apressórios. Anatomicamente, o talo é bastante simples, e consiste em numerosos filamentos cenocíticos que se ramificam, entrelaçando-se entre si, fusionados na região nodal. Os filamentos ramificamse lateralmente em apêndices terminais denominados

\footnotetext{
*Autor para correspondência: gabrieldonascimentosantos@yahoo.com; ajmcnunes2000@gmail.com

Editor responsável: Alessandro Rapini

Submetido: 28 out. 2014; aceito: 8 abr. 2015

Publicação eletrônica: 20 maio 2015; versão final: 25 maio 2015
}

utrículos. A reprodução pode ser assexuada, por fragmentação ou por desenvolvimento a partir de filamentos rizoidais, ou sexual do tipo holocárpica. A reprodução sexuada é considerada rara em Halimeda; das 43 espécies (Guiry \& Guiry 2015), apenas nove têm sua reprodução conhecida (Hillis-Colinvaux 1980). Isso pode estar relacionado com o fato desses organismos também se reproduzirem assexuadamente por fragmentação vegetativa, e por darem preferência por esse modo de reprodução (Walters et al. 2002), que pode conferir uma economia energética para o indivíduo. Embora Halimeda seja um gênero conspícuo e fácil de ser reconhecido no campo, a identificação de suas espécies é difícil, estimulando a busca de métodos que auxiliem na taxonomia do grupo (Verbruggen et al. 2005).

A microscopia eletrônica de varredura tem se mostrado de grande valor na taxonomia de macroalgas calcárias. A calcificação muitas vezes não possibilita o corte ou dissociação anatômica e a descalcificação prévia impossibilita a visualização das estruturas e ornamentações formadas pela deposição do calcário na superfície dessas algas. Diversos trabalhos permitiram a observação de caracteres úteis à taxonomia de vários grupos, como nos gêneros de algas calcárias articuladas vermelhas Tricleocarpa (J. Ellis \& Sol.) Huisman \& Borow. (Afonso-Carrillo et al. 1998), Corallina L. e Haliptilon (Decne.) Lindl. (Garbary \& Johansen 1982), algas calcárias incrustantes (Costa 2013), e algas verdes, como no próprio gênero Halimeda (BandeiraPedrosa et al. 2004a,b; Amorim et al. 2006), e no 
gênero Udotea J.V. Lamour. (Littler \& Littler 1990; Amorim et al. 2006), o que reforça a importância do seu uso em trabalhos taxonômicos com algas calcárias.

A flora de algas marinhas bentônicas é exuberante no Nordeste, caracterizado por águas oligotróficas e abundância de substratos duros, propícios ao crescimento de macroalgas marinhas (Horta et al. 2001). A Região abriga uma grande diversidade de ambientes litorâneos, sobretudo na Bahia, estado que apresenta uma flora marinha rica. O litoral da Bahia é o mais extenso do Brasil, com $1.103 \mathrm{~km}$ de extensão (Coordenação de Desenvolvimento do Turismo 1999), compreendendo praias arenosas, recifes de corais, formações de arenito, costões rochosos e manguezais. Dessa maneira, o litoral da Bahia é uma região prioritária para levantamentos florísticos (Nunes 2005).

$\mathrm{O}$ gênero Halimeda ainda carece de estudos aprofundados no litoral da Bahia, onde se destaca apenas o estudo de Amorim et al. (2006); os demais estão limitados basicamente a inventários florísticos (Martins et al. 1991; Altamirano \& Nunes 1997; Nunes 1998; Nunes et al. 1999, 2001; Marins et al. 2008; Andrade 2012; Costa et al. 2012; Santos et al. 2013). Embora Bandeira-Pedrosa et al. (2004a) tenham realizado uma revisão taxonômica para o gênero, salientando sua distribuição no litoral brasileiro, principalmente no Nordeste, detalhes acerca da distribuição de suas espécies no litoral da Bahia ainda são incompletos. Neste estudo, apresentamos o tratamento taxonômico de Halimeda para o litoral do estado da Bahia.

\section{MATERIAL E MÉTODOS}

Estações de Coleta. Foi examinado o material proveniente de coletas no litoral da Bahia entre os anos de 2012 e 2013 ( 22 excursões no mediolitoral e 2 no infralitoral) e amostras coletadas entre os anos de 1960 e 2011, depositadas no Herbário Alexandre Leal Costa (ALCB) e no Laboratório de Algas Marinhas (LAMAR), ambos do Instituto de Biologia da Universidade Federal da Bahia, além de materiais dos herbários Lauro Pires Xavier (JPB), da Universidade do Estado da Bahia (HUNEB), da Universidade Federal do Rio de Janeiro (RFA) e da Universidade de São Paulo (SPF), abrangendo coletas de 68 estações no mediolitoral e 45 no infralitoral, em 17 municípios do litoral do estado. As coletas no mediolitoral seguiram as técnicas usuais para Ficologia Marinha (Nunes 2010). As praias foram visitadas durante as marés baixas de sizígia, com base na Tábua de Marés do Ministério da Marinha do Brasil (http://www.mar.mil. $\mathrm{br} / \mathrm{dhn} / \mathrm{chm} /$ box-previsao-mare/tabuas/). As coletas no infralitoral foram feitas em parceria com a Central de Tratamento de Efluentes Líquidos (CETREL), com o uso de dragas de arrasto tipo Holme e de mordedura tipo Petersen.
Estudos em laboratório. O material coletado foi encaminhado ao LAMAR e triado a olho nu. Para a identificação dos táxons em nível infragenérico, consultou-se obras comumente utilizadas para o gênero (Yamada 1941; Joly 1967; Hillis 1959; Littler \& Littler 2000; Barata 2004; Bandeira-Pedrosa et al. 2004a,b; Verbruggen et al. 2005; Amorin et al. 2006). A análise do material foi realizada com auxílio de estereomicroscópio Leica ${ }^{\odot}$ - Zoom 2000, microscópio óptico Olympus ${ }^{\odot}-$ CX 22 e captura Olympus $^{\mathcal{O}}-$ CX 31 com câmera acoplada Q Imaging $^{\mathcal{O}}$ - Go Series, utilizando o programa Q Imaging ${ }^{\mathscr{C}}-\mathrm{Q}$ Capture PRO 7, e microscópio eletrônico de varredura $\left(\mathrm{JEOL}^{\mathbb{O}}\right.$ - JSM 6390 LV). Para as ilustrações, utilizou-se máquina fotográfica digital Sony ${ }^{\mathcal{O}}$ Cyber-Shot DSC S2000.

Os materiais herborizados foram separados dos que estavam em meio líquido (formol a 4\%) com estereomicroscópio e microscópio óptico. O material herborizado foi reidratado em solução contendo água e detergente líquido. As amostras foram descalcificadas por imersão em ácido clorídrico $20 \%$ ou ácido nítrico $0,6 \mathrm{M}$, finalizando apenas com o desprendimento total das bolhas de gás carbônico. As lâminas para microscopia foram montadas a partir da dissociação dos filamentos e secção longitudinal, realizadas com auxílio de lâminas de barbear e estiletes.

Para Microscopia Eletrônica de Varredura, os espécimes que estavam em meio líquido foram separados dos herborizados, pois as algas em meio líquido (formalina 4\%) tiveram que secar em estufa para serem fragmentadas e posicionadas no stub. As amostras passaram então pelo processo de metalização com ouro (Gold Sputtering of Samples), com atmosfera estabilizada em 50 mTor de Argônio (Denton Vacuum ${ }^{\circ}$ - Desk IV) e 5 min de exposição, conforme protocolo padrão do Centro de Pesquisas Gonçalo Moniz da Fundação Oswaldo Cruz (FIOCRUZ/BA).

A classificação taxonômica segue Wynne (2011). O basônimo e o protólogo estão de acordo com Guiry e Guiry (2015).

\section{TRATAMENTO TAXONÔMICO}

\section{Halimeda J.V. Lamour.}

Plantas calcificadas, articuladas, verdes, amarronzadas ou esbranquiçadas, eretas ou prostradas, solitárias ou formando tufos; fixas ao substrato por um apressório discoide ou bulboso, ou por múltiplos apressórios difusos nos segmentos. Talo sem diferenciação em lâmina e estipe, constituído por segmentos de formas variadas (região internodal), separados por constrições nítidas e flexíveis, pedunculadas ou sésseis (região nodal). Segmentos ramificados em um ou em vários planos, subcilíndricos, discoides, cuneados, reniformes, trapezoides, trilobados, ou intermediários entre estes. Região internodal do talo 
constituída por região medular, composta de filamentos cenocíticos entrelaçados e ramificados dicotomicamente, terminando em utrículos que, aderidos lateralmente entre si, mesmo após a descalcificação, formam a região cortical. Região nodal formada por sifões medulares, com paredes espessadas, apresentando fusão nodal curta (até $100 \mu \mathrm{m}$ compr.) ou longa (mais de $100 \mu \mathrm{m}$ compr.), em grupos de 2 ou 3, ou todos os sifões do nó. Algumas espécies apresentam poros inconspícuos situados na fusão dos filamentos, sifões moniliformes, ou pequenas projeções ocorrendo logo acima do ponto de fusão dos sifões.

São caracteres anatômicos importantes para a taxonomia de Halimeda: a forma e o diâmetro dos utrículos em vista superficial e seu comprimento em vista longitudinal, bem como o aspecto da fusão nodal (Tabela 1). A morfologia externa pode ajudar na identificação das espécies, mas a plasticidade fenotípica pode dificultar a separação entre pares de espécies semelhantes, como Halimeda opuntia $\times H$. gracilis, $H$. incrassata $\times H$. simulans, $H$. cuneata $\times H$. discoidea, $H$. cuneata $\times H$. tuna e $H$. tuna $\times H$. discoidea. Essas dificuldades taxonômicas, entretanto, podem ser facilmente solucionadas com base na anatomia (veja também Bandeira-Pedrosa et al. 2004a).

\section{Chave de identificação}

1. Fixação por um único apressório bulboso, sifões da região nodal fusionados em um único grupo, com poros.

2. Segmentos basais geralmente cilíndricos, segmentos apicais pouco calcificados, utrículos primários com mais de $50 \mu \mathrm{m}$ diâm.

4. H. incrassata

2'. Segmentos basais geralmente subcuneados ou reniformes, segmentos apicais fortemente calcificados, utrículos primários com até $50 \mu \mathrm{m}$ diâm.

6. H. simulans

1'. Fixação por um ou vários apressórios não bulbosos, sifões da região nodal fusionados em grupos de 2 ou 3 , sem poros.

3. Talo fortemente calcificado, fixação por múltiplos apressórios.

4. Fusão nodal longa, mais de $100 \mu \mathrm{m}$ compr. .... . . 3. H. gracilis

4'. Fusão nodal curta, até $100 \mu \mathrm{m}$ de compr. 5. H. opuntia

3'. Talo leve a moderadamente calcificado, fixação por um único apressório.

5. Segmentos discoides a reniformes, utrículos secundários inflados .............. 2. H. discoidea

5'. Segmentos cuneados, reniformes a subcilíndricos, utrículos secundários não inflados.

6. Segmentos basais cilíndricos, região nodal pedunculada ....................... 1. H. cuneata

6'. Segmentos basais subcuneados a reniformes, região nodal séssil
1. Halimeda cuneata K. Hering, Flora 29 (14): 209. 1846.

Figuras 1 e 2.

Plantas moderadamente calcificadas, verdeescuras, esbranquiçadas quando secas, eretas, solitárias, até $15 \mathrm{~cm}$ alt., fixas ao substrato por um apressório discoide. Região internodal com os 2 ou 3 primeiros segmentos cilíndricos, aparentando um estipe, os demais planos, cuneados, subcuneados, discoides ou trapezoides, lisos, brilhantes, margens inteiras, até $20 \mathrm{~mm}$ larg. e $15 \mathrm{~mm}$ compr.; ramificação esparsa a densa, dicotômica, tricotômica ou irregular; região medular formada por sifões longitudinais, moniliformes, tortuosos ou retilíneos, densamente entrelaçados, ramificados; região cortical com até 3 camadas de utrículos. Região nodal pedunculada, espessa, semelhante a almofada, com sifões moniliformes e pequenas projeções. Fusão nodal curta ou longa, em grupos de 2 ou 3 sifões. Seção longitudinal do talo: utrículos primários em forma de taça, 100-135 $\mu \mathrm{m}$ compr., sendo 2-4 utrículos primários suportados por cada utrículo secundário de 95-110 $\mu \mathrm{m}$ compr. Vista superficial do talo: utrículos primários em arranjo poligonal, 25-55 $\mu \mathrm{m}$ diâm., ângulos definidos, paredes espessas, ocasionalmente fusionados em grupos de 2 ou 3. Exemplares férteis encontrados em estágio gametofítico, apresentando gametóforos produzidos a partir de utrículos primários, que possuem até 15 gametângios pedunculados, até $300 \mu \mathrm{m}$ compr. e $100 \mu \mathrm{m}$ diâm.

Encontrada no mediolitoral, em substrato consolidado, Halimeda cuneata é o representante mais comum do gênero e mais frequente no litoral da Bahia. Tem sido frequentemente confundida com outras espécies, como $H$. discoidea e $H$. tuna, das quais difere por apresentar os dois primeiros segmentos basais nitidamente cilíndricos, aparentando um pequeno estipe, região nodal pedunculada, frequentemente apresentando a estrutura com aspecto de "almofada" (Bandeira-Pedrosa et al., 2004b) e pela presença de sifões moniliformes com paredes espessas.

Neste estudo, Halimeda cuneata foi a única espécie em que foram observados gametófitos férteis, cujas estruturas estão de acordo com o observado por Bandeira-Pedrosa et al (2004a), porém com mais gametângios por gametóforo (até 15 vs. até 7). Os exemplares analisados estão de acordo com as descrições de Hillis (1959) e Littler \& Littler (2000) para o Caribe, Bandeira-Pedrosa et al. (2004a,b) para o Brasil e Amorin et al. (2006) para a Ilha de Itaparica, no estado da Bahia.

Material selecionado - Cairu, Guarapuá, 11 nov. 2000, M.E.C. Ramos (ALCB 53395); Camaçari, Praia de Busca Vida, 7 abr. 2012, G.N. Santos \& O.S. Nascimento (ALCB 103400); Camamu, Barra Grande e Pedra Furada, 21 e 22 jan 1984, J.P.P. Santos (SPF 29717); Caravelas, Ilha de Siriba, 27 nov. 1984, G.J.P. Mitchell (RFA 7224); Entre Rios, Porto do Sauípe, 8 maio 2012, G.N. Santos \& O.S. Nascimento (ALCB 103401); Esplanada, Baixio, 12 out. 2000, J.M.C. Nunes (ALCB 103535); Ilheus, 


\begin{tabular}{|c|c|c|c|c|c|c|c|}
\hline Caracteres\Espécies & H. cuneata & H. discoidea & H. tuna & H. incrassata & H. simulans & H. gracilis & H. opuntia \\
\hline Hábito & Ereto & Ereto & Ereto & Ereto & Ereto & Ereto ou prostrado & Prostrado \\
\hline Tamanho & Até $15 \mathrm{~cm}$ alt. & Até $8 \mathrm{~cm}$ alt. & Até $15 \mathrm{~cm}$ alt. & Até $10 \mathrm{~cm}$ alt. & Até $15 \mathrm{~cm}$ alt. & Até $10 \mathrm{~cm}$ alt. & Até $30 \mathrm{~cm}$ compr. \\
\hline Ramificação & $\begin{array}{l}\text { Densa, em vários } \\
\text { planos }\end{array}$ & $\begin{array}{l}\text { Esparsa, em um só } \\
\text { plano }\end{array}$ & $\begin{array}{l}\text { Densa, em vários } \\
\text { planos }\end{array}$ & $\begin{array}{l}\text { Densa, em um só } \\
\text { plano }\end{array}$ & $\begin{array}{l}\text { Densa, em um só } \\
\text { plano }\end{array}$ & $\begin{array}{l}\text { Esparsa, em um só } \\
\text { plano }\end{array}$ & Densa, em vários planos \\
\hline Apressório & Discoide & Filamentoso & Discoide & Bulboso & Bulboso & Filamentoso & Filamentoso \\
\hline Forma dos segmentos basais & Cilíndrica & Cilíndrica & $\begin{array}{l}\text { Subcuneada a } \\
\text { subcilíndrica }\end{array}$ & Cilíndrica & Cilíndrica & Variada & Variada \\
\hline Calcificação & Moderada & Leve a moderada & Moderada & Forte & Forte & Forte & Forte \\
\hline Camadas de utrículos & Até 3 & Até 2 & Até 3 & Até 2 & Até 4 & Até 2 & Até 5 \\
\hline $\begin{array}{l}\text { Forma dos utrículos } \\
\text { primários em vista frontal }\end{array}$ & $\begin{array}{l}\text { Poligonal, ângulos } \\
\text { definidos e paredes } \\
\text { espessas }\end{array}$ & $\begin{array}{l}\text { Poligonal, ângulos } \\
\text { definidos e paredes } \\
\text { delgadas }\end{array}$ & $\begin{array}{l}\text { Poligonal, ângulos } \\
\text { definidos e paredes } \\
\text { delgadas }\end{array}$ & $\begin{array}{l}\text { Poligonal, ângulos } \\
\text { definidos e paredes } \\
\text { delgadas }\end{array}$ & $\begin{array}{l}\text { Poligonal, ângulos } \\
\text { definidos e paredes } \\
\text { delgadas }\end{array}$ & $\begin{array}{l}\text { Poligonal, ângulos } \\
\text { arredondados e paredes } \\
\text { delgadas }\end{array}$ & $\begin{array}{l}\text { Poligonal, ângulos } \\
\text { arredondados e paredes } \\
\text { delgadas }\end{array}$ \\
\hline $\begin{array}{l}\text { Diâm. dos utrículos } \\
\text { primários em vista frontal }\end{array}$ & $25-55 \mu \mathrm{m}$ & $40-85 \mu \mathrm{m}$ & $30-60 \mu \mathrm{m}$ & $50-90 \mu \mathrm{m}$ & $18-50 \mu \mathrm{m}$ & $20-50 \mu \mathrm{m}$ & $12-25 \mu \mathrm{m}$ \\
\hline $\begin{array}{l}\text { Compr. dos utrículos } \\
\text { primários em vista } \\
\text { longitudinal }\end{array}$ & $100-135 \mu \mathrm{m}$ & $60-85 \mu \mathrm{m}$ & $60-110 \mu \mathrm{m}$ & $60-100 \mu \mathrm{m}$ & $22-50 \mu \mathrm{m}$ & $47-92 \mu \mathrm{m}$ & $22-32 \mu \mathrm{m}$ \\
\hline $\begin{array}{l}N^{0} \text { de utrículos primários } \\
\text { sobre secundários }\end{array}$ & Até 4 & Até 6 & Até 6 & Até 4 & Até 4 & Até 8 & Até 2 \\
\hline Fusão nodal & $\begin{array}{l}\text { Curta ou extensa, em } \\
\text { grupos de } 2 \text { ou } 3 \\
\text { filamentos }\end{array}$ & $\begin{array}{l}\text { Curta ou extensa, em } \\
\text { grupos de } 2 \text { ou } 3 \\
\text { filamentos }\end{array}$ & $\begin{array}{l}\text { Curta ou extensa, em } \\
\text { grupos de } 2 \text { ou } 3 \\
\text { filamentos }\end{array}$ & $\begin{array}{l}\text { Curta, formada por } \\
\text { todos os filamentos }\end{array}$ & $\begin{array}{l}\text { Curta, formada por } \\
\text { todos os filamentos }\end{array}$ & $\begin{array}{l}\text { Extensa, em grupos de } 2 \\
\text { ou } 3 \text { filamentos }\end{array}$ & $\begin{array}{l}\text { Curta, em grupos de } 2 \\
\text { ou } 3 \text { filamentos }\end{array}$ \\
\hline
\end{tabular}




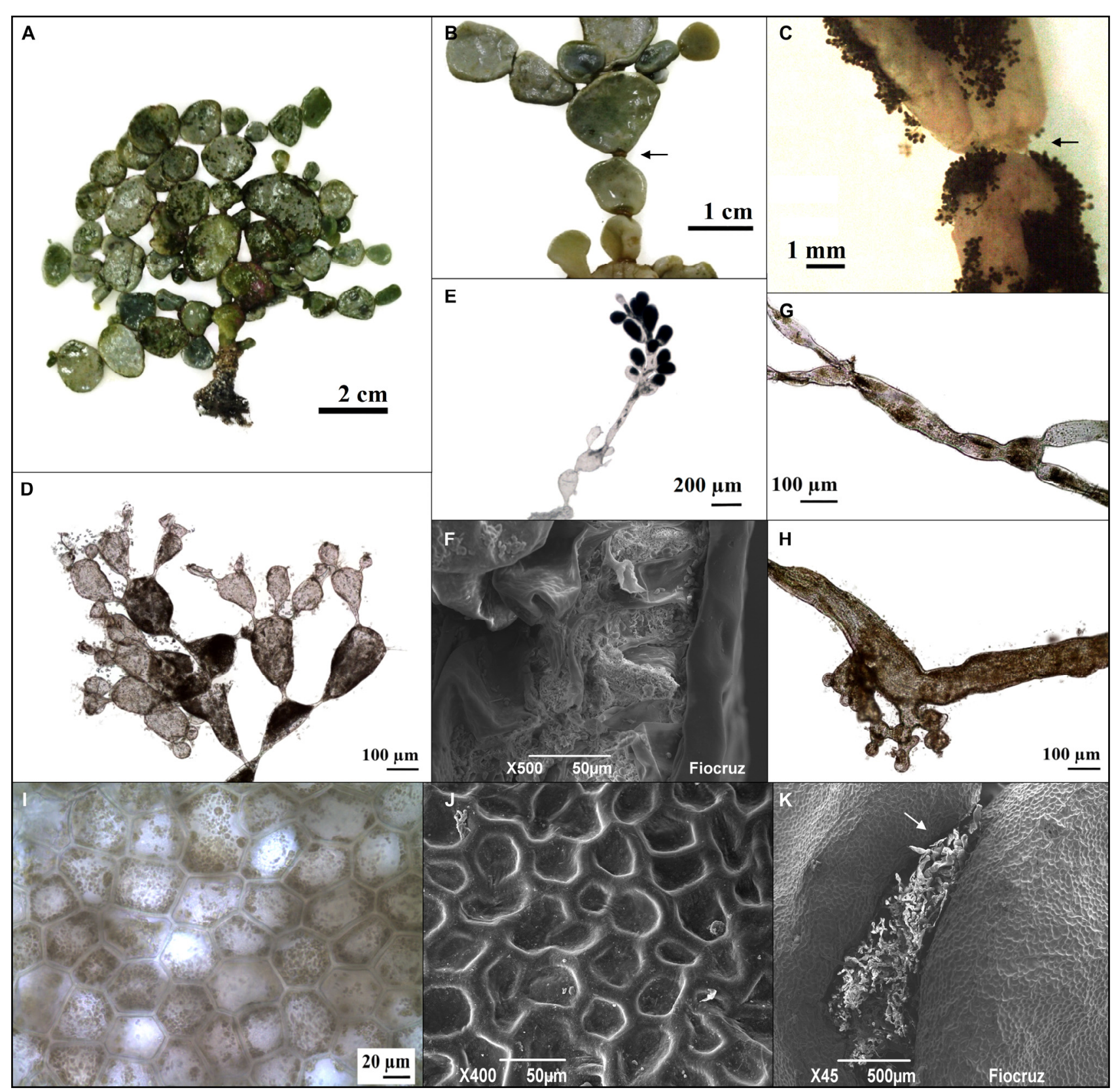

Figura 1. Halimeda cuneata: A- aspecto geral; B- detalhe da estrutura com aspecto de almofada na região nodal (seta); C- detalhe de dois segmentos intermodais recobertos por inúmeros gametóforos (seta - região nodal); D- utrículos em vista longitudinal; E- gametóforo ramificado, produzido a partir da camada de utrículos primários, com gametângios; F- corte transversal do talo, com detalhe para os utrículos; G- fusão nodal extensa entre dois sifões; H- detalhe do espessamento em sifão da região nodal; I, J- utrículos primários em vista superficial; K- região nodal, com detalhe para estrutura com aspecto de almofada (seta) (F, J, K- Microscopia Eletrônica de Varredura).

distrito de Olivença, 27 nov. 1981, Y. Ugadim (SPF 28354); Lauro de Freitas, Vilas do Atlântico, 24 maio 1997, J.M.C. Nunes (ALCB 48451); Maraú, Praia de Saquara, 1 ago. 1982, M.L. Christoffersen (JPB 11385); Mata de São João, Praia do Forte, 5 nov. 2009, G.N. Santos et al. (HUNEB 12721); Nova Viçosa, Ilha de Coroa Vermelha, 15 out. 1982, M.L. Christoffersen (RFA 1563); Porto Seguro, Arraial d'Ajuda, 21 fev. 1981, G.J.P. Mitchell (RFA 927); Prado, Ponta do Moreira, 5 jun. 2001, J.M.C. Nunes et al. (ALCB 103538); Salvador, Praia de Stella Maris, 2 dezembro 2014, J.M.C. Nunes (ALCB 109498); Santa Cruz Cabrália, Arakakaí, 9 mar. 2001, J.M.C. Nunes \& G.M. Lyra (ALCB 57460); Uruçuca, Serra Grande, 8 out. 1985, J.M.C. Nunes (ALCB 22271); Vera Cruz, Barra Grande, 22 ago. 1990, A.P.M. Nunes (HUNEB 2022).
2. Halimeda discoidea Decne., Ann. Sci. Nat., Bot. 18: 96. 1942.

Figuras 3 e 4.

Plantas leve a moderadamente calcificadas, verdeclaras a esbranquiçadas, eretas, solitárias, até $8 \mathrm{~cm}$ alt., fixas ao substrato por um apressório filamentoso diminuto. Região internodal com os 2 primeiros segmentos basais menores ou deformados, ocasionalmente cilíndricos, aparentando um estipe, os demais discoides a reniformes, lisos e opacos, com margens frequentemente erodidas, até $25 \mathrm{~mm}$ larg. e 20 mm compr.; ramificação esparsa, em um só plano, di a tricotômica; região medular formada por sifões 


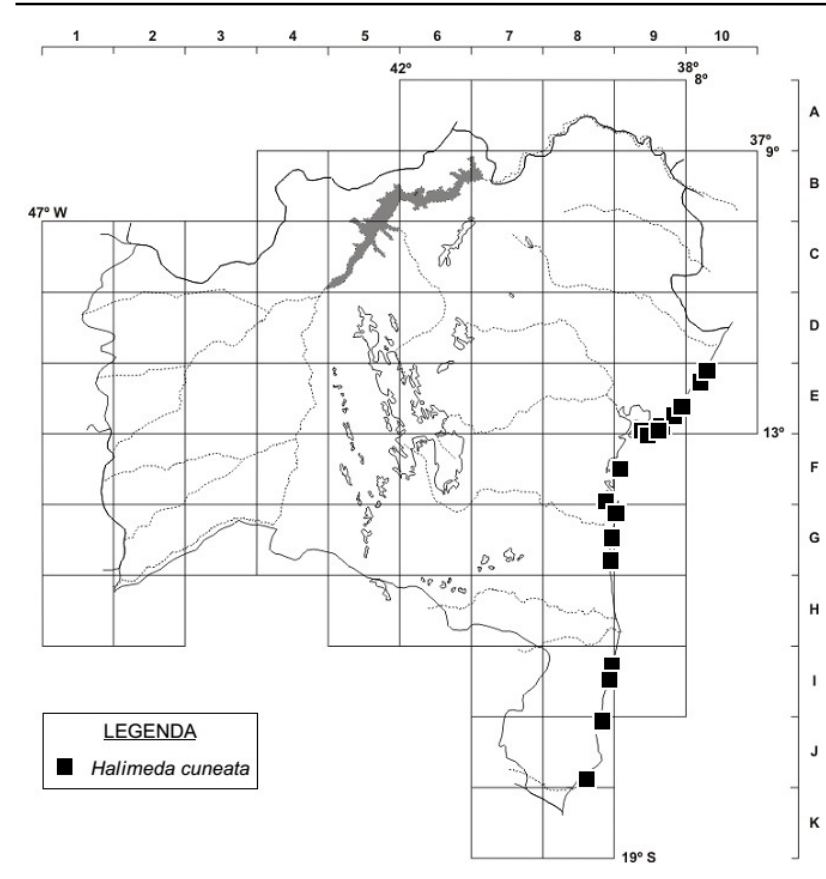

Figura 2. Mapa de distribuição de Halimeda cuneata no litoral do estado da Bahia.

longitudinais, cilíndricos, entrelaçados; região cortical com até 2 camadas de utrículos. Região nodal séssil. Fusão nodal curta ou longa, em grupos de 2 ou 3 sifões. Seção longitudinal do talo: utrículos primários com ápice truncado, 60-85 $\mu \mathrm{m}$ compr., sendo 4-6 utrículos primários suportados por cada utrículo secundário de 95-250 $\mu \mathrm{m}$ compr., inflados a subglobosos. Vista superficial do talo: utrículos primários em arranjo poligonal, 40-85 $\mu \mathrm{m}$ diâm., ângulos definidos, paredes delgadas. Não foram observados exemplares férteis.

Encontrada predominantemente no infralitoral, crescendo em substratos arenosos ou biodetríticos, em profundidades de até $30 \mathrm{~m}$. Os exemplares analisados estão de acordo com as diferenças batimétricas descritas por Bandeira-Pedrosa et al. (2004a), onde os indivíduos coletados em profundidades menores apresentam maior grau de calcificação, tonalidade verde mais viva e ramificação mais densa. Neste estudo, não foram encontrados gametófitos férteis que permitissem a observação da morfologia dos gametóforos e dos gametângios (para detalhes dessas estruturas, veja Bandeira-Pedrosa et al 2004a). As demais características morfológicas e anatômicas estão de acordo com as descrições de Hillis (1959) e Littler \& Littler (2000) para o Caribe, bem como de BandeiraPedrosa et al. (2004a) para o Brasil. Registros fósseis da espécie são relatados para o Mioceno, Plioceno e Pleistoceno (Dragastan et al. 2002).

Material selecionado - Camaçari, \#A4 (12\%44'12,03”'S, 38 05'12,53”W), 19 jul. 2000, CETREL (ALCB 103760); \#C4 (12'45'49,07'S, 38 $\left.06^{\circ} 34,26^{\prime} \mathrm{W}\right)$, jan. 2013, CETREL (ALCB 107078); \#D4 (1246'40,49”'S,3807'16,25”W), fev. 2003, CETREL (ALCB 103759); \#E5 (1247'56”S, 3807'20”W), fev. 2011,

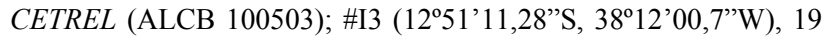

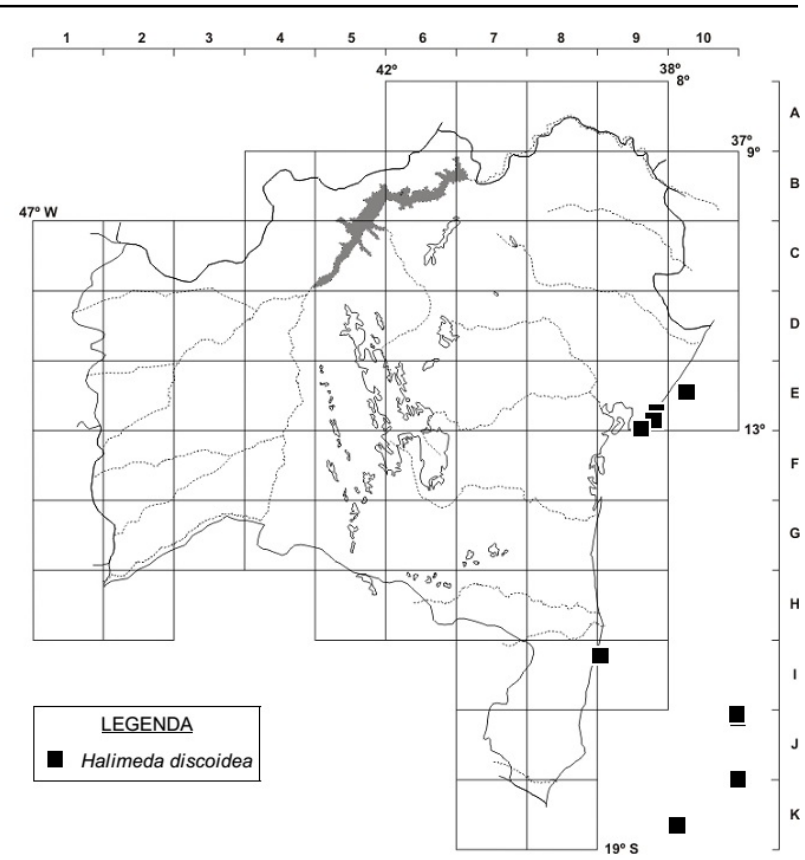

Figura 3. Mapa de distribuição de Halimeda discoidea no litoral do estado da Bahia.

fev. 2002, CETREL (ALCB 57477); Arembepe, 17 mar. 1994, Cepemar (ALCB 22839); 18/05/1993 (HUNEB 9421); Caravelas, Praia Sudeste, 31 jan. 1979, Equipe Morg. (RFA 5003); Estação 15C (1801'S, 3653'W), 13 nov. 1997, Projeto Revizee (RFA 28810); Estação 17 (18³9'48”S, 3752'13”W), 29 jun. 2001, Projeto Revizee (RFA 28696); Monte Marinho Rodgers, Estação 0404 (17 $08^{\prime}$ S, 36 $\left.48^{\circ} \mathrm{W}\right), 6$ jun. 1999, Projeto Revizee (RFA 28681); Estação 10 (1705'54'’S, 3645'08'W), 7 jul. 2001, Projeto Revizee (RFA 28691); Estação 10C (1703'59'S, 3648'28'”), 14 jun. 1997, Projeto Revizee (RFA 28547); Estação $11 \mathrm{C}\left(17^{\circ} 04^{\prime} \mathrm{S}\right.$, 36'53'W), 14 out. 1997, Projeto Revizee (RFA 28811); Santa Cruz Cabrália, Coroa Alta, 3 jan. 1979, E.C. Oliveira (SPF 51158).

3. Halimeda gracilis Harv. ex J. Agardh, Acta Universit. Lund. 23(2): 1. 1887.

Figuras 5 e 6.

Plantas fortemente calcificadas, cremeesbranquiçadas, eretas ou prostradas, solitárias ou formando grupos, até $10 \mathrm{~cm}$ compr., fixas ao substrato por um sistema de múltiplos apressórios filamentosos diminutos. Região internodal com segmentos discoides, reniformes ou trapezoides, lisos, brilhantes, quebradiços, margens inteiras, onduladas ou levemente lobadas, até $10 \mathrm{~mm}$ larg. e $6 \mathrm{~mm}$ compr.; ramificação esparsa, em um só plano, di ou tricotômica; região medular formada por sifões longitudinais, cilíndricos, entrelaçados; região cortical com até 2 camadas de utrículos. Região nodal séssil. Fusão nodal longa, em grupos de 2 ou 3 sifões. Seção longitudinal do talo: utrículos primários 47-92 $\mu \mathrm{m}$ compr., sendo até 8 utrículos primários suportados por cada utrículo secundário de 166-250 $\mu \mathrm{m}$ compr., clavados. Vista superficial do talo: utrículos primários arredondados, 20-50 $\mu \mathrm{m}$ diâm., paredes delgadas. Não foram observados exemplares férteis. 


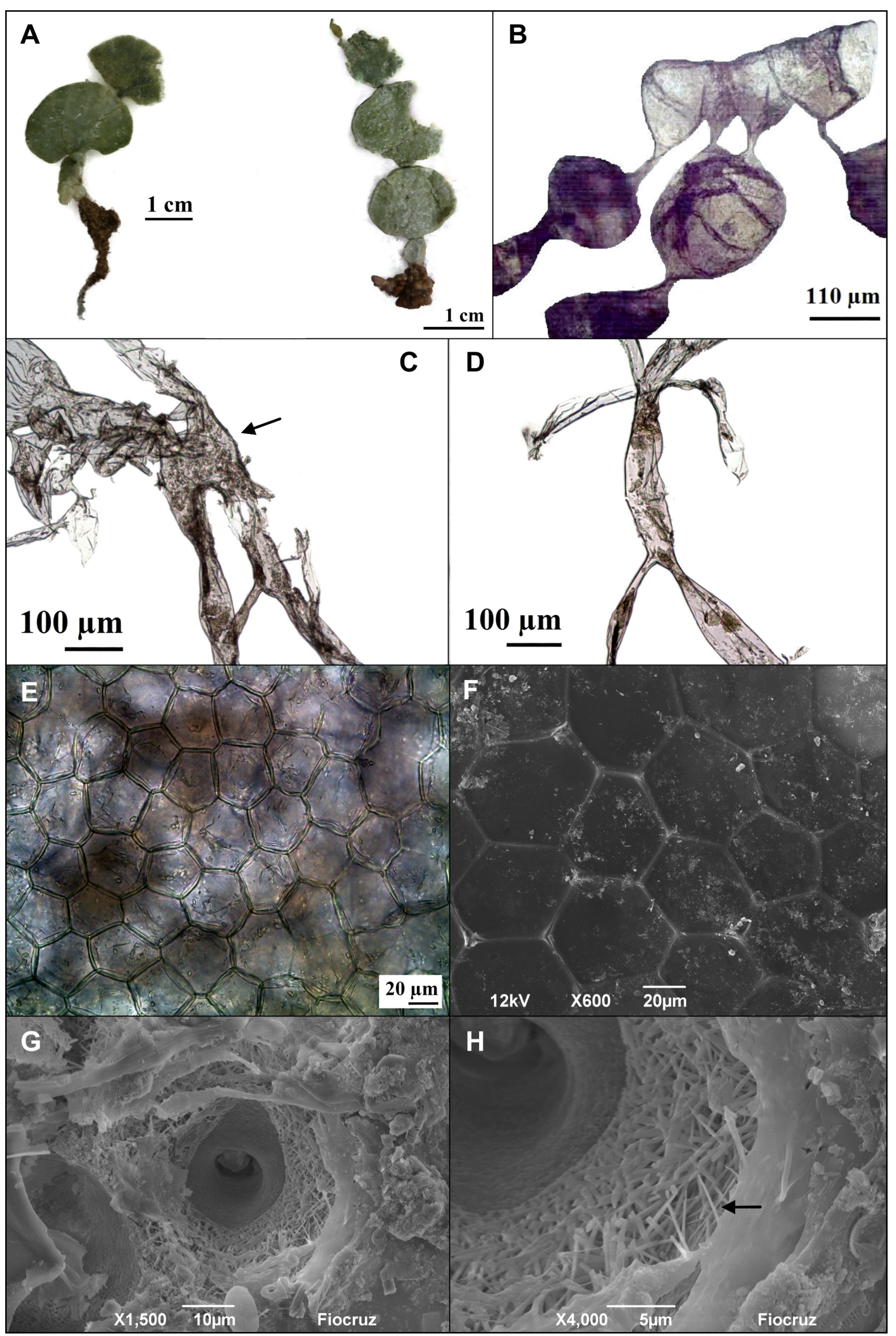

Figura 4. Halimeda discoidea: A- aspecto geral; B- utrículos em vista longitudinal; C- fusão nodal curta entre dois sifões (seta); D- fusão nodal extensa entre dois sifões; E, F- utrículos primários em vista superficial; G- detalhe do esqueleto de calcário que recobre o utrículo primário; H- cristais de aragonita na forma de agulhas da região do utrículo primário (seta) (F-H- Microscopia Eletrônica de Varredura). 


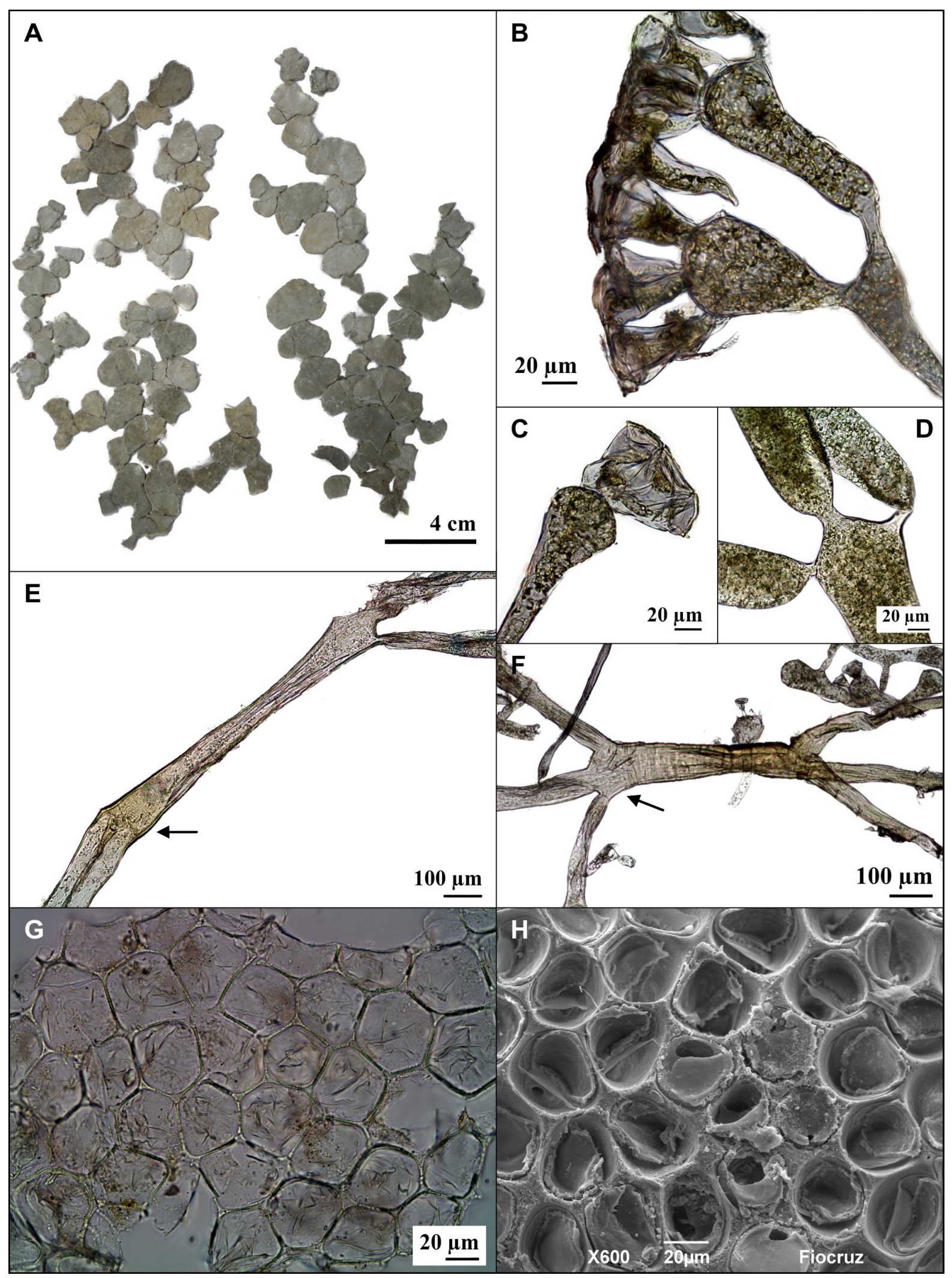

Figura 5. Halimeda gracilis: A- aspecto geral; B, C- utrículos em vista longitudinal; D- detalhe da constrição às vezes presente nas ramificações dos filamentos; E, F- detalhe da fusão nodal extensa entre dois e três sifões, respectivamente (setas); G- utrículos primários em vista superficial; H- vista superficial da capa calcária na qual se inserem os utrículos primários (Microscopia Eletrônica de Varredura).

Encontrada no infralitoral, em profundidades entre 10 e $40 \mathrm{~m}$, em substrato arenoso e biodetrítico. Halimeda gracilis assemelha-se a $H$. opuntia, e essas espécies são frequentemente confundidas; todavia, tornam-se fáceis de serem distinguidas pela forma dos utrículos primários em vista superficial, que são arredondados, maiores e com paredes delgadas em $H$. gracilis, e pela fusão nodal, que é longa em $\mathrm{H}$. gracilis 


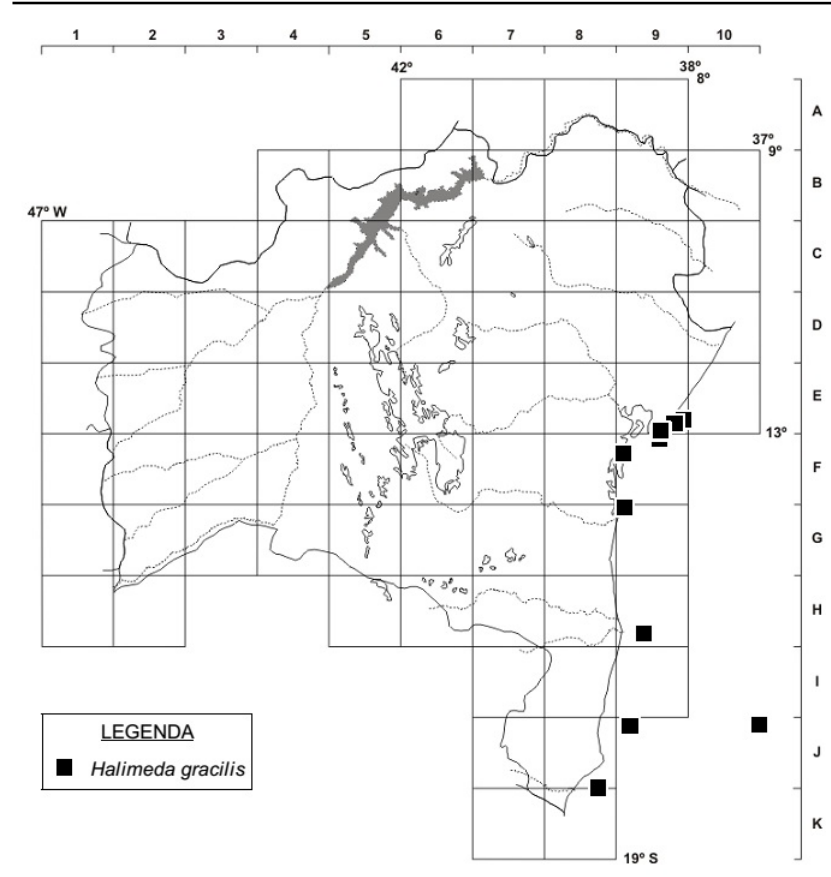

Figura 6. Mapa de distribuição de Halimeda gracilis no litoral do estado da Bahia.

e curta em $H$. opuntia. Os exemplares analisados estão de acordo com as descrições de Bandeira-Pedrosa et al. (2004a) para o Brasil, e Littler \& Littler (2000) para o Caribe. Entretanto, o material estudado aqui apresenta até $6 \mathrm{~mm}$ compr. e $10 \mathrm{~mm}$ larg., enquanto os exemplares descritos por Bandeira-Pedrosa et al. (2004a) possuem até $11 \mathrm{~mm}$ compr. e $18 \mathrm{~mm}$ larg., e os exemplares descritos por Littler \& Littler (2000) até $15 \mathrm{~mm}$ compr. e $9 \mathrm{~mm}$ larg. Registros fósseis da espécie são relatados para o Mioceno (Dragastan et al. 2002).

Material selecionado - Banco Royal Charlotte, 15\%49'40"S, 38³6'26”'W, 21 jun. 2002, Projeto Revizee (RFA 28686); Camaçari, \#A4 (12\%44'12,03”'S, 3805'12,53”W), fev. 2011, CETREL (ALCB 100374); \#C3 (12 45'33”S, 38 07'10”'W), 20 fev. 2002, CETREL (ALCB 100388); \#D3 (12046'15”S, 38 05'55”W), jan. 2013, CETREL (ALCB 107088); \#F6 (1249'08,74”S, 3807'29,96”W), 25 jul. 2000, CETREL (ALCB 57445); \#H5 (1250'26”'S, 3809'26”W), ago. 2011, CETREL (ALCB 99917); Praia de Arembepe, 8 mar. 1994, Cepemar (ALCB 22169); Caravelas, Estação 0404 (1708'S, 3848’W), 6 jun. 1999, Projeto Revizee (RFA 28685); Monte

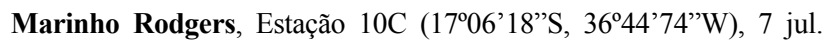

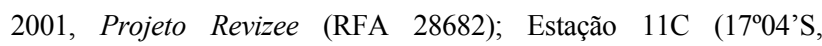
36 53'W), 14 out. 1997, Projeto Revizee (RFA 28814); Salvador, 1304'18'S, 38'23'38'W, 23 jun. 2002, Projeto Revizee (RFA 28545); Estação 18 (13 $\left.03^{\circ} 16,8^{\prime \prime} \mathrm{S}, 38^{\circ} 03^{\prime} 14,1^{\prime \prime} \mathrm{W}\right), 17$ jan. 2003, EMBASA (ALCB 60952); Estação OC-12 (1258'33,4”'S, 38²2'16,6”W), maio 2003, EMBASA (ALCB 60956); Praia de Placafor, 7 mar. 2007, G.M. Amado-Filho \& R. Bahia (ALCB 99754).

4. Halimeda incrassata (J. Ellis) J.V. Lamour., Poisson LXXXIV: 599. 1816. Corallina incrassata J. Ellis, Nouv. Bull. Sci. Soc. Philom. 3: 186. 1812. Figuras 7 e 8 .

Plantas fortemente calcificadas na base e porção mediana do talo, levemente calcificadas na região apical, verde-claras a esbranquiçadas, eretas, solitárias, até $10 \mathrm{~cm}$ alt., fixas ao substrato por um apressório bulboso. Região internodal com os 2 ou 3 primeiros segmentos cilíndricos, aparentando um estipe, o seguinte flabelar e maior, os demais planos, cilíndricos, subcilíndricos, subcuneados a reniformes, lisos, brilhantes, margens inteiras, onduladas ou lobadas, até $10 \mathrm{~mm}$ larg. e $6 \mathrm{~mm}$ compr.; ramificação esparsa a densa, em um só plano, di ou tricotômica ou irregular; região medular formada por sifões longitudinais, cilíndricos, entrelaçados; região cortical com até 2 camadas de utrículos. Região nodal séssil. Fusão nodal curta, formada por todos os sifões fusionados em um único grupo, apresentando poros inconspícuos. Seção longitudinal do talo: utrículos primários com 50-100 $\mu \mathrm{m}$ compr., sendo até 4 utrículos primários suportados por cada utrículo secundário de 44-77 $\mu \mathrm{m}$ compr. Vista superficial do talo: utrículos primários em arranjo poligonal, 50-90 $\mu \mathrm{m}$ diâm., ângulos definidos, paredes delgadas. Não foram observados exemplares férteis.

Encontrada em substrato arenoso ou biodetrítico, no mediolitoral em poças de maré, e no infralitoral entre 20 e $60 \mathrm{~m}$ de profundidade. Os exemplares analisados estão de acordo com as descrições de Hillis (1959) e Littler \& Littler (2000) para o Caribe, e BandeiraPedrosa et al. (2004a) para o Brasil. Todavia, diferem do observado por Bandeira-Pedrosa et al. (2004a) por apresentarem poros inconspícuos na fusão nodal. Registros fósseis da espécie são relatados para o Mioceno (Dragastan et al. 2002).

Material examinado - Caravelas, Estação 15C ( $18^{\circ} 01^{\prime}$ 'S, 36 $\left.{ }^{\circ} 53^{\prime} \mathrm{W}\right), 13$ nov. 1997 Projeto Revizee (RFA 28813); Monte Submarino Hotspur, Estação 15C (1801'22'S, 3553'28'W), 13 nov. 1997, Projeto Revizee (RFA 28683); Salvador, Estação OC2 (12'58'33,40”S, 38²2'16,60”'W), 17 jan. 2003, EMBASA (ALCB 57915).

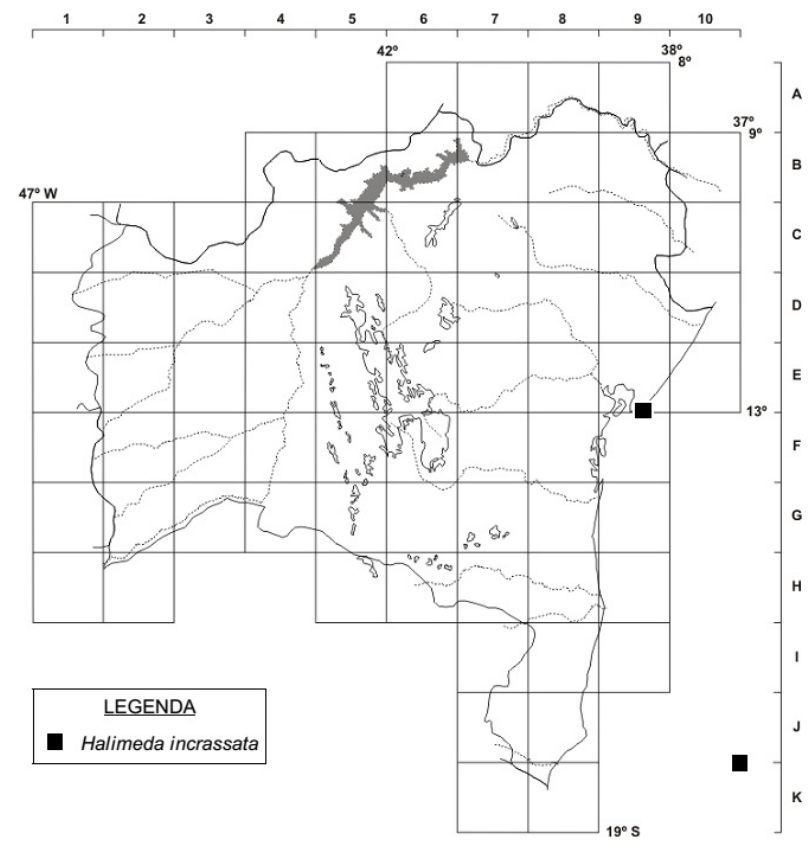

Figura 7. Mapa de distribuição de Halimeda incrassata no litoral do estado da Bahia. 


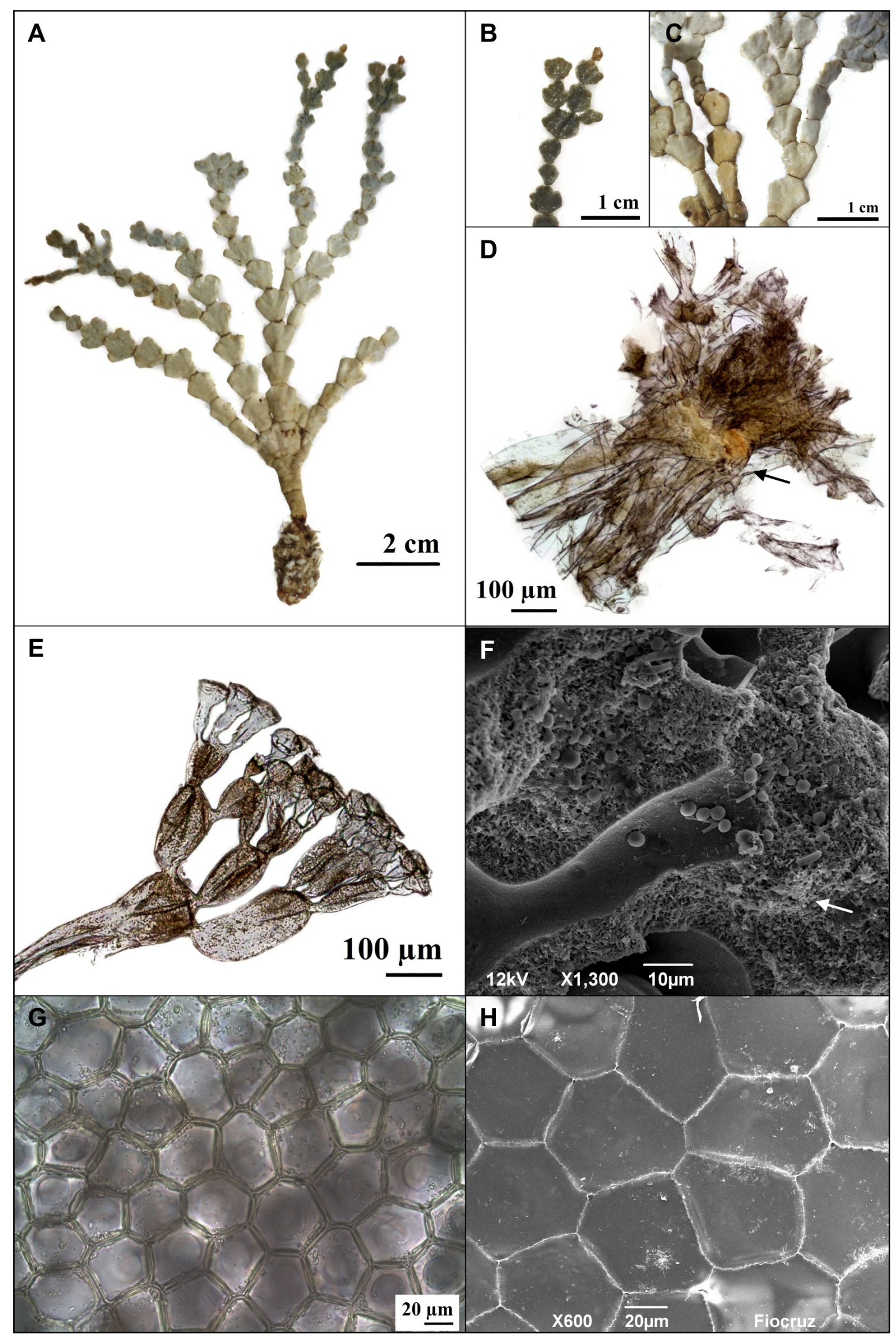

Figura 8. Halimeda incrassata: A- aspecto geral; B- ápice dos segmentos com leve calcificação; C- porção mediana dos segmentos com região nodal séssil; D- fusão nodal curta com todos os sifões com poros inconspícuos no ponto de fusão (seta); E- utrículos em vista longitudinal; F- utrículos em vista longitudinal, com detalhe para cristais de aragonita na forma de agulhas (seta); G, H- utrículos primários em vista superficial (F, H- Microscopia Eletrônica de Varredura). 
5. Halimeda opuntia (L.) J.V. Lamour., Poisson LXXXIV: 599. 1816. Corallina opuntia L., Nouv. Bull. Sci. Soc. Philom. 3: 186. 1812.

Figuras 9 e 10.

Plantas fortemente calcificadas, verde-claras a esbranquiçadas, eretas ou prostradas, formando tufos, até $30 \mathrm{~cm}$ compr., fixas ao substrato por um sistema de múltiplos apressórios filamentosos diminutos. Região internodal com segmentos achatados, discoides, reniformes, trapezoides ou trilobados, lisos, brilhantes, margens inteiras, onduladas, crenadas ou levemente lobadas, até $10 \mathrm{~mm}$ larg. e $6 \mathrm{~mm}$ compr.; ramificação densa, em vários planos, irregular; região medular formada por sifões longitudinais, cilíndricos, entrelaçados; região cortical com 3-5 camadas de utrículos. Região nodal séssil. Seção longitudinal do talo: utrículos primários $22-32 \mu \mathrm{m}$ compr., sendo 2 utrículos primários suportados por cada utrículo secundário de $25-50 \mu \mathrm{m}$ compr. Vista superficial do talo: utrículos primários arredondados, $12-25 \mu \mathrm{m}$ diâm.,

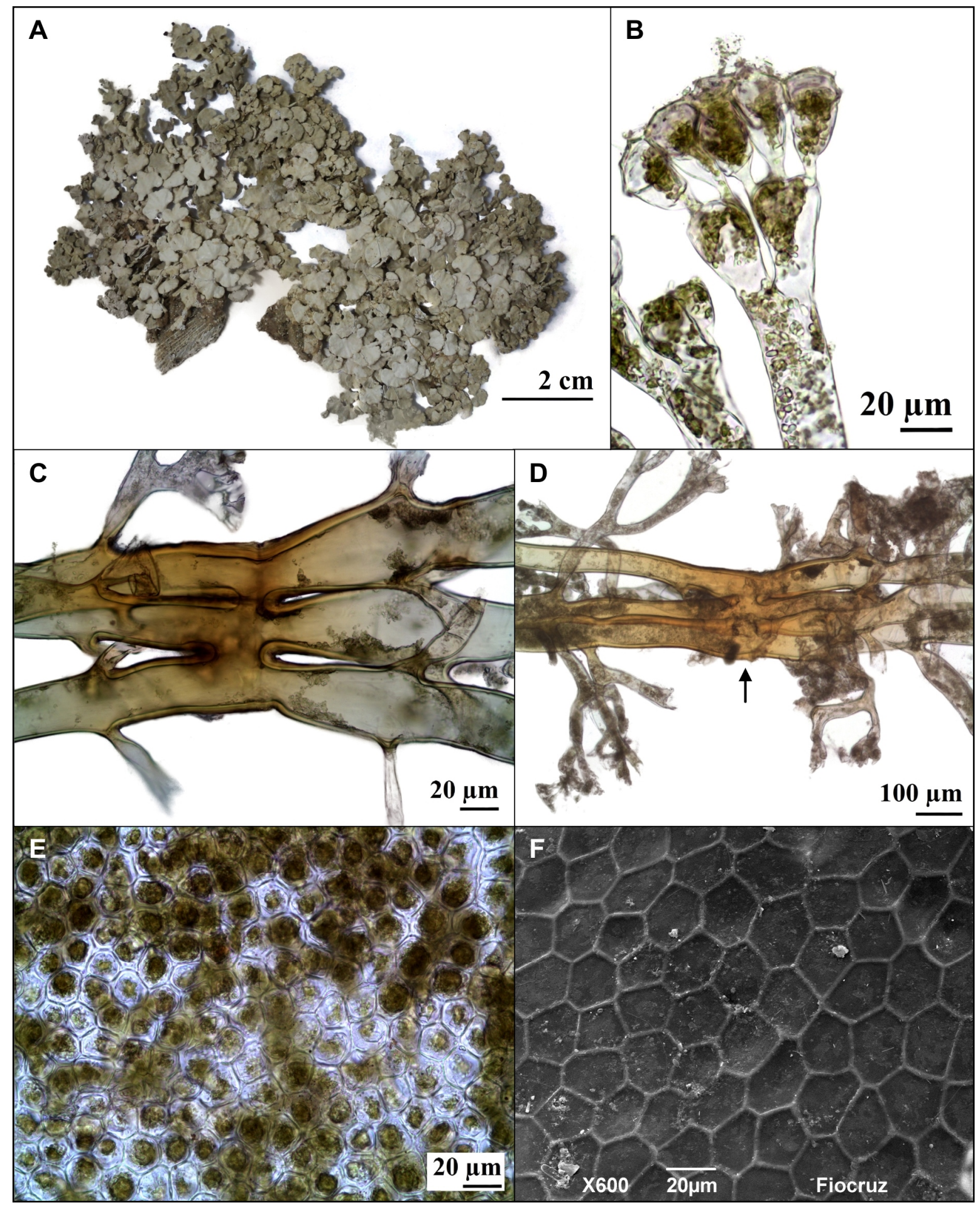

Figura 9. Halimeda opuntia: A- aspecto geral; B- detalhe dos utrículos em vista longitudinal; C- detalhe da fusão nodal curta entre três sifões; D- detalhe da fusão nodal curta entre quatro sifões (seta); E, F- utrículos primários em vista superficial (F- Microscopia Eletrônica de Varredura). 
paredes delgadas. Fusão nodal curta, em grupos de 2 ou 3(4) sifões. Não foram observados exemplares férteis.

Encontrada no mediolitoral e no infralitoral, até 10 $\mathrm{m}$ de profundidade, em substrato consolidado. Halimeda opuntia é a espécie mais comum do gênero, considerada cosmopolita. Os exemplares analisados aqui estão de acordo com as descrições de Hillis (1959) e Littler \& Littler (2000) para o Caribe, BandeiraPedrosa et al. (2004a) para o Brasil, e Amorin et al. (2006) para a Ilha de Itaparica, no estado da Bahia. Registros fósseis da espécie são relatados para o Plioceno e Pleistoceno (Dragastan et al. 2002).

Material selecionado - Cairu, Guarapuá, 11 nov. 2000, M.E.C. Ramos (ALCB 53197); Morro de São Paulo, 26 ago. 2000, J.M.C. Nunes et al. (HUNEB 10106); Camaçari, Praia de Busca Vida, 7 abr. 2012, G.N. Santos \& O.S. Nascimento (ALCB 103498); Praia de Guarajuba, 24 mar. 2012, G.N. Santos \& O.S. Nascimento (ALCB 106970); Mata de São João, Praia do Forte, 23 jul. 2009, J.S. Freitas et al. (HUNEB 12843); Salvador, Praia de Amaralina, 2 abr. 1952, E. Nonato (SPF 4426); Praia da Barra, 4 nov. 1986, G.B. Bastos (ALCB 17462); Praia de Itapuã, 14 nov. 2012, G.N. Santos \& L.M.S. Cruz (ALCB 103890); Praia de Ondina, 23 jul. 2013, G.N. Santos et al. (ALCB 109557); Praia de Placafor, 10 ago. 1984, G.P. Borges (ALCB 17271); Praia de Stella Maris, 2 out. 2012, G.N. Santos et al. (ALCB 103480); Vera Cruz, Barra do Gil, 28 nov. 1981, Y. Ugadim (SPF 29736); Barra do Pote, 10 jan. 1997, J.M.C. Nunes (ALCB 48447); Caramuanas, 25 mar. 2012, T.A. Caires (ALCB 103360); Praia de Aratuba, 16 abr. 2004, J.M.C. Nunes (ALCB 68409); Praia da Penha, 16 out. 2012, G.N. Santos et al. (ALCB 103551).

6. Halimeda simulans M. Howe, Bull. Tor. Bot. Club 34: 503. 1907.

Figuras 11 e 12.

Plantas fortemente calcificadas, verdes, eretas, solitárias, até $15 \mathrm{~cm}$ alt., fixas ao substrato por um

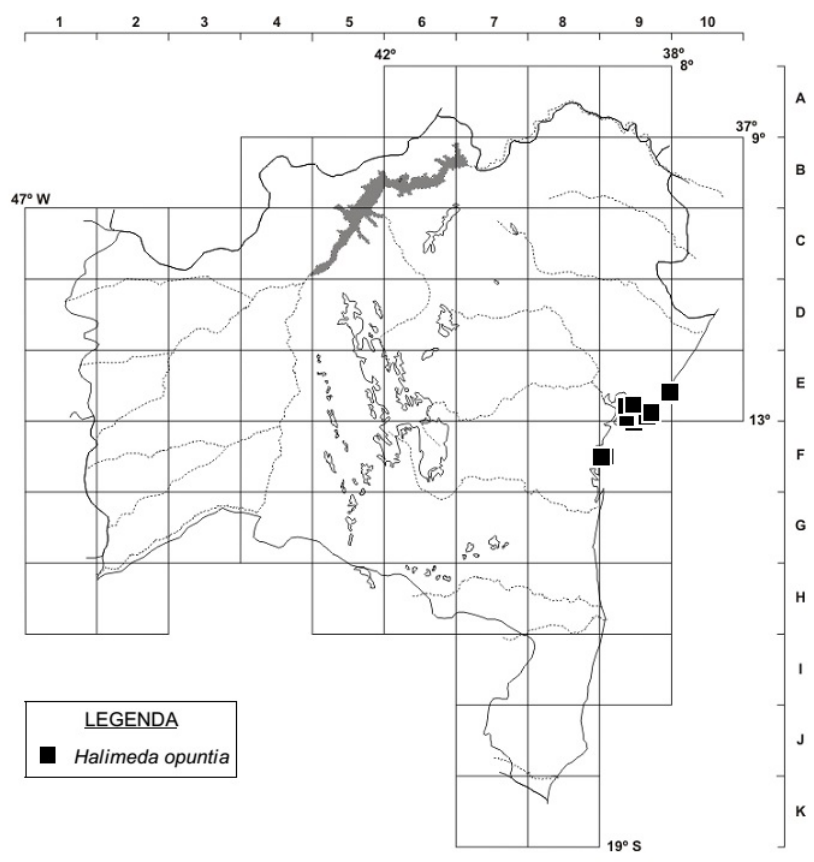

Figura 10. Mapa de distribuição de Halimeda opuntia no litoral do estado da Bahia. apressório bulboso. Região internodal, os 2 primeiros segmentos cilíndricos, aparentando um estipe, o seguinte flabelar e maior, os demais planos, subcuneados a reniformes, até $10 \mathrm{~mm}$ larg. e $6 \mathrm{~mm}$ compr., lisos, brilhantes, margens inteiras; ramificação densa, em um só plano, di ou tricotômica, ocasionalmente irregular; região medular formada por sifões longitudinais, cilíndricos, entrelaçados; região cortical com até 4 camadas de utrículos. Região nodal séssil. Seção longitudinal do talo: utrículos primários 22-50 $\mu \mathrm{m}$ compr., sendo até 4 utrículos primários suportados por cada utrículo secundário de 50-90 $\mu \mathrm{m}$ compr. Vista superficial do talo: utrículos primários em arranjo poligonal, 18-50 $\mu \mathrm{m}$ diâm., com ângulos definidos, paredes delgadas. Fusão nodal curta, formada por todos os sifões fusionados em um único grupo, com poros inconspícuos. Não foram observados exemplares férteis.

Encontrada no mediolitoral e no infralitoral, em substrato arenoso, sendo a maioria dos indivíduos em profundidades de até $25 \mathrm{~m}$, porém alguns encontrados em profundidades de até $60 \mathrm{~m}$. Halimeda simulans assemelha-se a $H$. incrassata, porém difere nitidamente quanto ao diâmetro dos utrículos primários, intensidade da calcificação dos segmentos apicais, e morfologia dos segmentos basais. Os exemplares analisados estão de acordo com Hillis (1959) e Littler e Littler (2000) para o Caribe, Bandeira-Pedrosa et al. (2004a) para o Brasil e Amorin et al. (2006) para a Ilha de Itaparica no estado da Bahia. Registros fósseis da espécie são relatados para o Plioceno por Dragastan et al. (2002).

Material examinado - Cairu, Guarapuá, 11 nov. 2000, M.E.C. Ramos (ALCB 53433; 86442); Camaçari, \#A4 (1244'12,06"S, $38^{\circ} 05^{\prime} 12,53^{\prime \prime} \mathrm{W}$ ), fev. 2003, CETREL (ALCB 103880); jan. 2009,

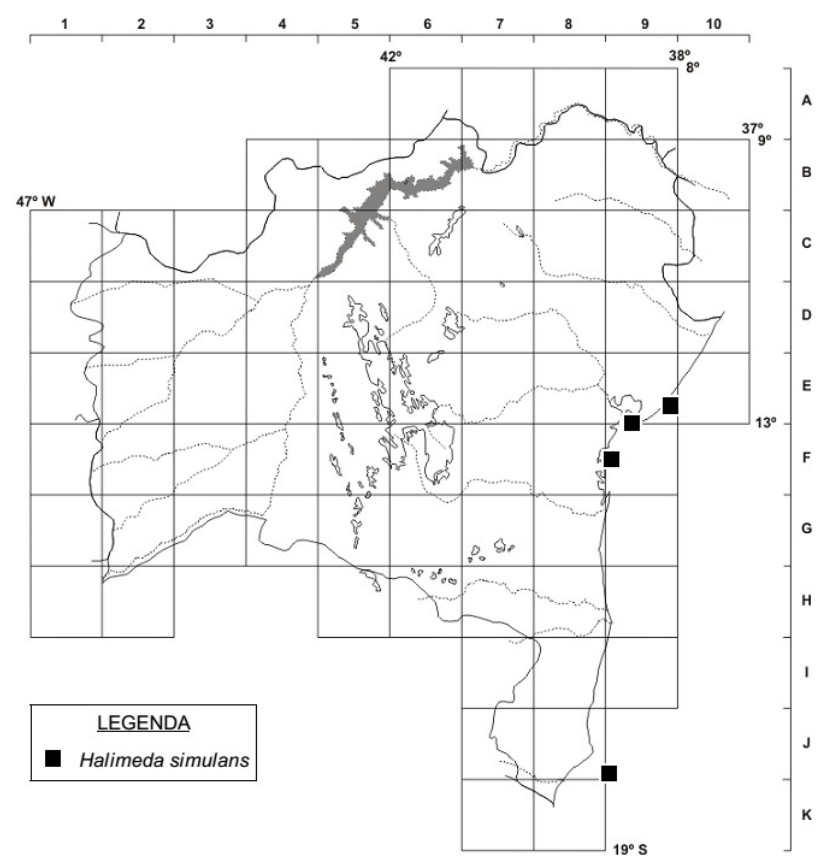

Figura 11. Mapa de distribuição de Halimeda simulans no litoral do estado da Bahia. 
CETREL (ALCB 98176); Caravelas, Ilha Guarita, 29 jan. 2008, B.N.T. Silva \& E.C. Oliveira (SPF 56789); Vera Cruz, Barra do Pote, 25 out. 2001, J.M.C. Nunes (ALCB 73465); Mar Grande, 9 ago. 1998, M.E. Bandeira-Pedrosa \& M.C. Accioly (ALCB 73411); 17 abr. 2000, J.M.C. Nunes et al. (ALCB 103712); 7 jul. 2000; M.C. Accioly (ALCB 73414); Praia da Penha, 10 set. 2006, J.M.C. Nunes (ALCB 73421); 16 out. 2012, G.N. Santos et al. (ALCB 103713).
7. Halimeda tuna (J. Ellis \& Sol.) J.V. Lamour., Poisson LXXXIV: 599. 1816. Corallina tuna J. Ellis \& Sol., Nouv. Bull. Sci. Soc. Philom. 3: 186. 1812.

Figuras 13 e 14.

Plantas moderadamente calcificadas, verde-escuras a verde-amarronzadas, eretas, solitárias, até $15 \mathrm{~cm}$ alt.,

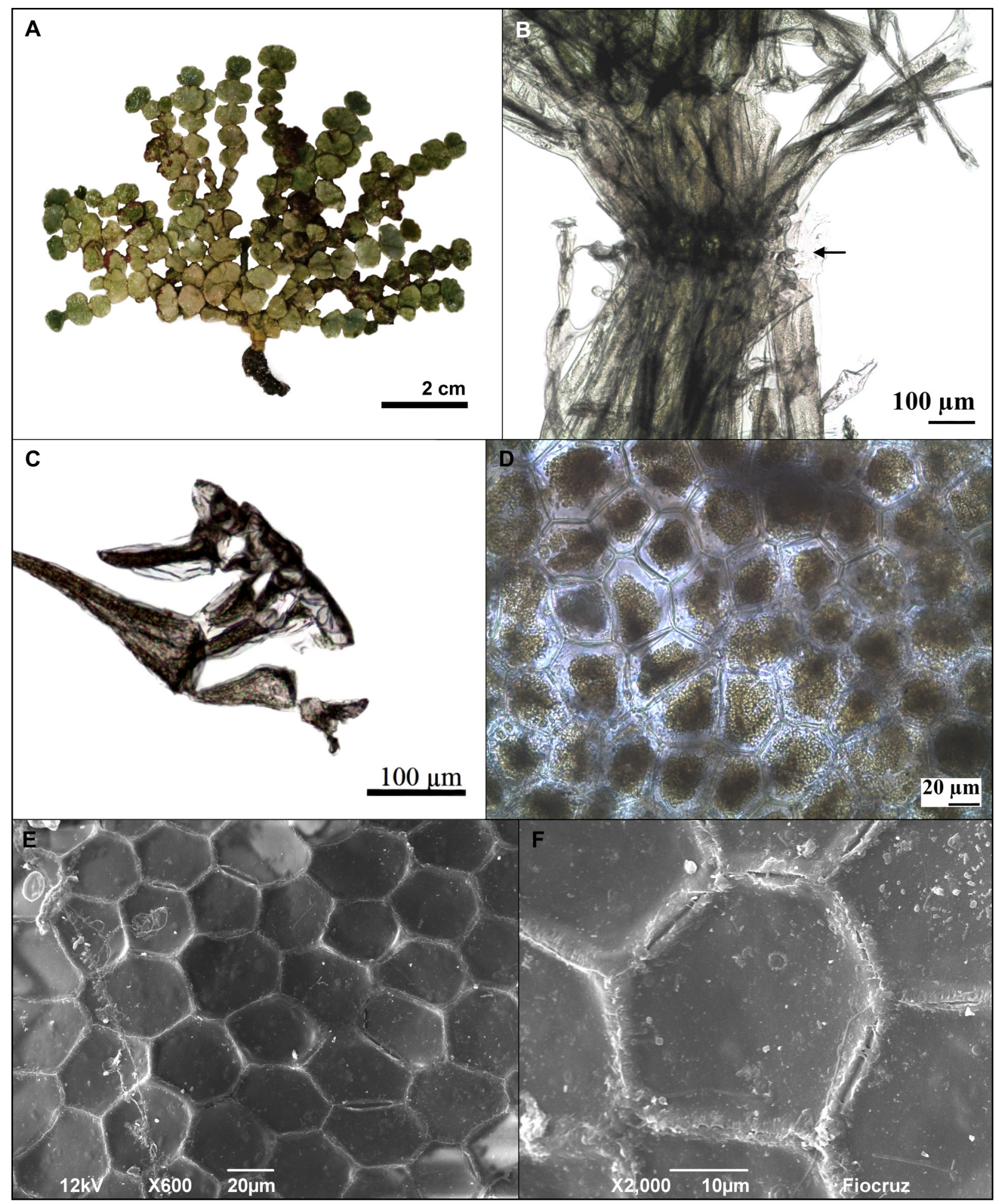

Figura 12. Halimeda simulans: A- aspecto geral; B- detalhe da fusão nodal curta com todos os sifões, e poros inconspícuos no ponto de fusão (seta); C- utrículos em vista longitudinal; D, E- utrículos primários em vista superficial; F- detalhe das paredes delgadas dos utrículos primários em vista superficial (E, F- Microscopia Eletrônica de Varredura). 


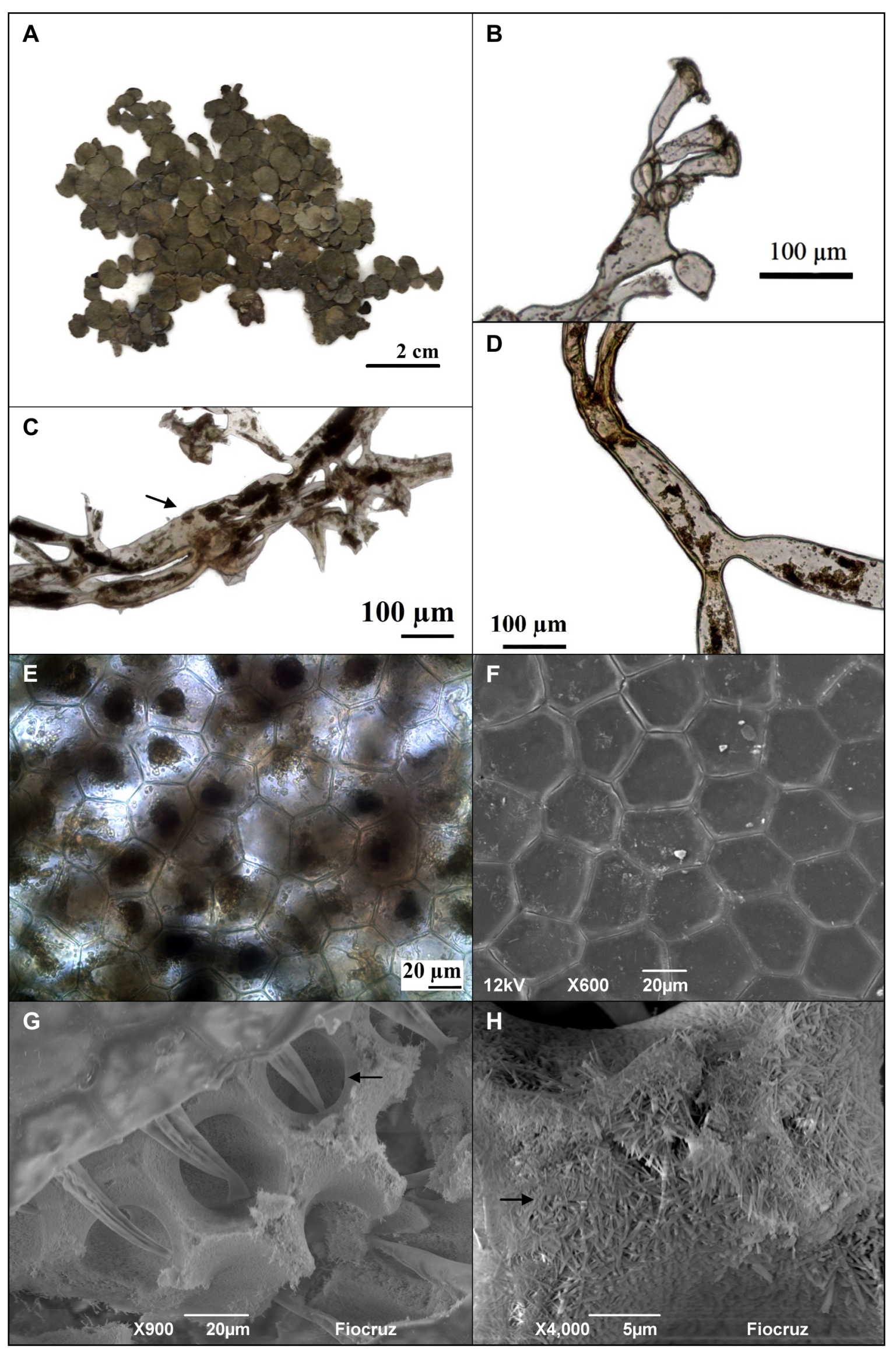

Figura 13. Halimeda tuna: A- aspecto geral; B- utrículos em vista longitudinal; C- detalhe da fusão nodal curta entre dois sifões (seta); D- detalhe da fusão nodal extensa entre dois sifões; E, F- utrículos primários em vista superficial; G- detalhe do esqueleto de calcário no qual os utrículos se inserem (seta); H- cristais de aragonita na forma de agulhas da região do utrículo primário (seta). (F-H- Microscopia Eletrônica de Varredura). 


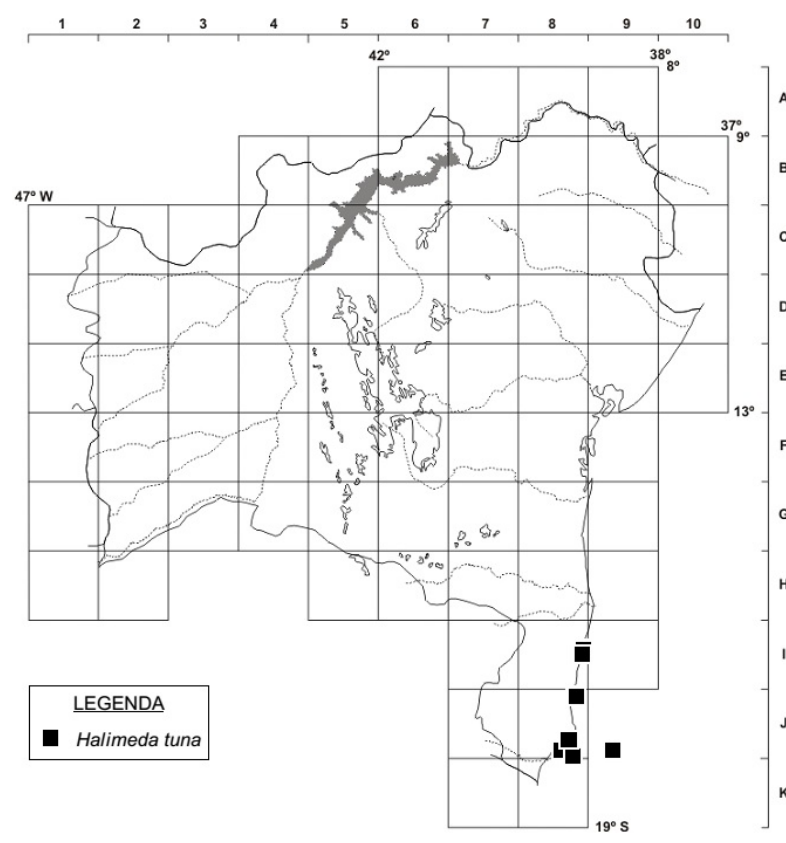

Figura 14. Mapa de distribuição de Halimeda tuna no litoral do estado da Bahia.

fixas ao substrato por apressório discoide. Região internodal, segmentos basais mais calcificados, subcuneados, subcilíndricos, os demais planos, discoides, reniformes, ou subcuneados, textura áspera, opacos, até $20 \mathrm{~mm}$ larg. e $11 \mathrm{~mm}$ compr.; ramificação esparsa a densa, di ou tricotômica; região medular formada por sifões longitudinais, cilíndricos, entrelaçados; região cortical com até 3(4) camadas de utrículos. Região nodal séssil. Seção longitudinal do talo: utrículos primários $60-110 \mu \mathrm{m}$ compr., sendo até 6 utrículos primários por utrículo secundário de 90 $170 \mu \mathrm{m}$ compr. Vista superficial do talo: utrículos primários em arranjo poligonal, 30-60 $\mu \mathrm{m}$ diâm., ângulos definidos, paredes delgadas. Fusão nodal extensa ou curta, em grupos de 2 ou 3 sifões. Não foram observados exemplares férteis.

Encontrada no mediolitoral, em poças de maré, sobre substratos arenosos, ou na região frontal do recife, crescendo em substrato rochoso. Os exemplares analisados estão de acordo com as descrições de Hillis (1959) e Littler \& Littler (2000) para o Caribe, e Bandeira-Pedrosa et al. (2004a) para o Brasil. Registros fósseis da espécie são relatados para o Mioceno e Pleistoceno (Dragastan et al. 2002).

Material examinado - Caravelas, Cordão ente Redonda e Siriba, 27 nov. 1984, M.A.O.F. Guerra (ALCB 107130; RFA 1706); Parcel das Paredes, 1 ago. 1984, A.I. Kanagawa (JPB 11380); 29 jan. 1988, G.J.P. Mitchell (ALCB 107124; RFA 4598); Nova Viçosa, Arrecifes, 15 dez. 1985, G.J.P. Mitchell (ALCB 107125; RFA 2041); 18 abr. 1988, G.J.P. Mitchell (ALCB 107126; RFA 4453); Ilha de Coroa Vermelha, 26 jan. 1988, G.J.P. Mitchell (ALCB 107131; RFA 4496); 19 abr. 1988, C.A.G. Nassar (ALCB 107128; RFA 4363); Porto Seguro, Mucugê, 12 mar. 2001, J.M.C. Nunes et al. (ALCB 52964); Parque Marinho do Recife de Fora, 11 mar. 2000, O.S. Costa Júnior (ALCB 48171); Ponta do Mutá, 16 out. 1982, M.L. Christoffersen (ALCB 107129; RFA 1567); Prado, Curumuxatiba, 4 jun. 2001, J.M.C. Nunes \& G.M. Lyra (ALCB 103711); recife entre Imbaçaba e Cumuruxatiba, 14 out. 1982, M.L. Christoffersen (JPB 11381).

\section{CONSIDERAÇõES FINAIS}

No presente estudo, foi possível identificar caracteres taxonomicamente importantes. Dentre os caracteres morfológicos, se destacam o hábito, a intensidade da calcificação, a forma do apressório e a morfologia dos segmentos e da região nodal, e dentre os caracteres anatômicos, se destacam a forma, diâmetro e tipo de ramificação dos sifões, a forma dos utrículos e a fusão nodal. Embora a identificação em Halimeda seja feita com base no conjunto de caracteres morfológicos, anatômicos, reprodutivos e ecológicos, a anatomia parece ter maior relevância, pois possibilita identificações mais precisas, incluindo a separação entre pares de espécies semelhantes.

\section{AgRAdeCIMENTOS}

Ao Programa de Pós-graduação em Biodiversidade Vegetal, pelo apoio financeiro às coletas; ao Laboratório de Algas Marinhas (LAMAR) do Instituto de Biologia da UFBA e ao Herbário Alexandre Leal Costa (ALCB), pela disponibilidade da infraestrutura; ao Centro de Pesquisas Gonçalo Muniz da Fundação Oswaldo Cruz (FIOCRUZ), pela disponibilidade do uso do microscópio eletrônico de varredura; aos herbários brasileiros que disponibilizaram seus exemplares para a pesquisa; à Fundação de Amparo à Pesquisa do Estado da Bahia (FAPESB); ao Sistema de Informação sobre a Biodiversidade Brasileira ( $\mathrm{SIBBr}-$ $\mathrm{N}^{\mathrm{o}}$ : 504208/2012-8); e ao Programa de Apoio a Núcleos Emergentes (PRONEM-FAPESB, T.O.PNE 0020/2011).

\section{REFERÊNCIAS}

Afonso-Carrillo, J.; Pérez, L.; Sansón, M. \& Reyes, J. 1998. Observaciones em Tricleocarpa cylindrica com el microscopio electrónico de barrido (Rhodophyta, Galaxauraceae). Vieraea 26: 87-91.

Altamirano, M. \& Nunes, J.M.C. 1997. Contribuiciones al macrofitobentos del município de Camaçari (Bahia, Brasil). Acta Botanica Malacitana 22: 211-215.

Amorin, P.R.R.; Moura, C.W.N. \& Moniz-Brito, K.L. 2006. Estudo morfo-taxonômico das espécies de Halimeda, Penicillus e Udotea (Bryopsidales, Chlorophyta) do recife de franja da Ilha de Itaparica, Bahia. In: Anais do Congresso Brasileiro de Ficologia e Simpósio Latino-Americano Sobre Algas Nocivas, 11. Itajaí, p. 35-54.

Andrade, N.A. 2012. O Papel da Declividade e Sedimentologia na Composição e Estrutura dos Bancos de Rodolitos Litoral Norte 
da Bahia, Brasil. Dissertação de Mestrado. Universidade do Estado da Bahia.

Bandeira-Pedrosa, M.E.; Pereira, S.M.B. \& Oliveira, E.C. 2004a. Taxonomy and distribution of the green algal genus Halimeda (Bryopsidales, Chlorophyta) in Brazil. Revista Brasileira de Botânica 27(2): 363-377.

Bandeira-Pedrosa, M.E.; Pereira, S.M.B.; Bouzon, Z.L. \& Oliveira, E.C. 2004b. Halimeda cuneata (Bryopsidales, Chlorophyta), a new record for the Atlantic Ocean. Phycologia 43(1): 50-57.

Barata, D. 2004. Cloroficeas Marinhas Bentônicas do Estado do Espirito Santo. Dissertação de Mestrado. Instituto de Botânica da Secretaria de Estado do Meio Ambiente.

Clifton, K.E. \& Clifton, L.M. 1999. The phenology of sexual reproduction by green algae (Bryopsidales) on Caribbean coral reefs. Journal of Phycology 35: 24-34.

Coordenação de Desenvolvimento do Turismo. 1999. Programa de Desenvolvimento Turístico da Bahia - oportunidades de investimento. Governo do Estado da Bahia, Salvador.

Costa, I.O.; Caires, T.A.; Pereira Filho, G.H. \& Nunes, J.M.C. 2012. Macroalgas bentônicas associadas a bancos de Hypnea musciformis (Wulfen) J.V. Lamour. (Rhodophyta Gigartinales) em duas praias do litoral baiano. Acta Botanica Brasilica 26(2): 493-507.

Costa, I.O. 2013. Estudos Taxonômicos em Algas Coralináceas Não Articuladas no Litoral Norte da Bahia, Brasil. Dissertação de Mestrado. Universidade do Estado da Bahia.

DeWreede, R. 2006. Biomechanical properties of coenocytic algae (Chlorophyta, Caulerpales). Science Asia 1(32): 57-62.

Dragastan, O.N.; Littler, D.S. \& Littler, M.M. 2002. Recent vs. fossil Halimeda species of Angaur Island, Palau and adjacent Western Pacific areas. Acta Palaeontologica Romaniae 1: 1-42.

Drew, E.A. 1983. Halimeda biomass, growth rates and sediment generation on reefs in the Central Great Barrier Reef Province. Coral Reefs 2: 101-110.

Garbary, D.J. \& Johansen, H.W. 1982. Scanning electron microscopy of Corallina and Haliptilon (Coralinaceae, Rhodophyta): surface features and their taxonomic implications. Journal of Phycology 18: 211-219.

Guiry, M.D. \& Guiry, G.M. 2015. AlgaeBase. World-wide electronic publication, National University of Ireland, Galway, Disponível em: http://www.algaebase.org; acesso em: 10 jan. 2015.

Hillis, L.W. 1959. A revision of the genus Halimeda (Order Aiphonales). Publications of the Institute of Marine Science 6: 322-403.

Hillis-Colinvaux, L. 1980. Ecology and taxonomy of Halimeda: primary producer of coral reefs. Advance Marine Biology 17: 1327.

Hillis-Colinvaux, L. 1986a. Deep water populations of Halimeda in the economy of an atoll. Bulletin of Marine Science 38(1): 155169.

Hillis-Colinvaux, L. 1986b. Distribution patterns of some Bryopsidales in the geologic past: their bearing on present distributions. Botanica Marina 29: 271-277.
Horta, P.A.; Amancio, E. \& Coimbra, C.S. 2001. Considerações sobre a distribuição e origem da flora de macroalgas marinhas brasileiras. Hoehnea 28(3): 243-265.

Joly, A.B. 1967. Gêneros de Algas Marinhas da Costa Atlântica Latino-Americana. Editora da Universidade de São Paulo, São Paulo.

Littler, D.S. \& Littler, M.M. 1990. Systematics of Udotea species (Bryopsidales, Chlorophyta) in the Tropical Weastern Atlantic. Phycologia 29(2): 206-252.

Littler, D.S. \& Littler, M.M. 2000. Caribbean Reef Plants. OffShore Graphics, Washington.

Marins, B.V.; Braliseiro, P.S.; Barreto, M.B.B.; Nunes, J.M.C.; Yoneshinge-Valentin, Y. \& Amado Filho, G.M.A. 2008. Subtidal benthic marine algae of The Todos os Santos Bay, Bahia State, Brazil. Oecologia Brasiliensis 12(2): 229242.

Martins, D.V.; Cordeiro-Marino, M.; Boccanera, N.B. \& Nunes, J.M.C. 1991. Clorofíceas marinhas bentônicas do Município de Salvador, Bahia, Brasil. Hoehnea 18(2): 115-133.

Nunes, J.M.C. 1998. Catálogo de algas marinhas bentônicas do Estado da Bahia. Acta Botanica Malacitana 23: 5-21.

Nunes, J.M.C. 2005. Rodoficeas Marinhas Bentônicas do Estado da Bahia, Brasil. Tese de Doutorado. Universidade de São Paulo.

Nunes, J.M.C. 2010. Taxonomia morfológica: metodologia de trabalho. In: A.G. Pedrini (org.), Macroalgas: uma introdução à taxonomia. Technical Books, Rio de Janeiro, p. 53-70.

Nunes, J.M.C.; Santos, A.C.C.; Minervino, A. \& Brito, K.S. 1999. Algas marinhas bentônicas do município de Ilhéus, Bahia, Brasil. Acta Botanica Malacitana 24: 5-12.

Nunes, J.M.C.; Santos, A.C.C.; Lyra, G.M.; Minervino-Netto, A. \& Pedreira, E.S. 2001. Marine benthic algae from Uruçuca, Bahia, Brazil. Acta Botanica Malacitana 26: 181-246.

Ries, J.B. 2005. Aragonite production in calcite seas: effect of seawater $\mathrm{Mg} / \mathrm{Ca}$ ratio on the calcification and growth of the calcareous alga Penicillus capitatus. Paleobiology 31(3): 445458.

Santos, G.N.; Nascimento, O.S.; Pedreira, F.A.; Rios, G.I.; Vasconcelos, J.N.C. \& Nunes, J.M.C. 2013. Análise qualiquantitativa das algas arribadas do norte do estado da Bahia, Brasil. Acta Botanica Malacitana 38: 13-24.

Verbruggen, H.; Clerck, O.; Cocquyt, E.; Kooistra, W.H.C.F. \& Coppejans, E. 2005. Morphometric taxonomy of siphonous green algae: a methodological study within the genus Halimeda (Bryopsidales). Journal of Phycology 41: 126-139.

Walters, L.J.; Smith, C.M.; Coyer, J.A.; Hunter, C.L.; Beach, K.S. \& Vroom, P.S. 2002. Asexual propagation in the coral reef macroalga Halimeda (Chlorophyta, Bryopsidales): production, dispersal and attachment of small fragments. Journal of Experimental Marine Biology 128: 47-65.

Wynne, M.J. 2011. A checklist of the benthic marine algae of the Tropical and Subtropical Western Atlantic: third revision. Nova Hedwigia 140: 1-166.

Yamada Y. 1941. On the species of Halimeda from Micronesia. Kagaku Nanyõ 4: 108-121. 


\section{LISTA DE EXSICATAS}

Accioly, M.C. s.n. ALCB 73414 (6); Amado-Filho, G.M. s.n. ALCB 99754 (3); Bandeira-Pedrosa, M.E. s.n. ALCB 73411 (6); Bastos, G.B. s.n. ALCB 17462 (5); Borges, G.P. s.n. ALCB 17271 (5); Caires, T.A. s.n. ALCB: 103360 (5), 103487 (1); CETREL s.n. ALCB: 57445 (3), 57477 (2), 57479 (3), 60707 (2), 98176 (6), 99867, 99917, 100374, 100388 (3), 100503, 103759, 103760 (2), 103880 (6), 107078 (2), 107088, 107089 (3); Cepemar s.n. ALCB: 22169 (3), 22839 (2), HUNEB 9421 (2); Christoffersen, M.L. s.n. ALCB 107129 (7), JPB: 11379 (1), 11381 (7), 11385 (1), RFA: 1563 (1), 1567 (7); Costa Júnior, O.S. s.n. ALCB 48171 (7); EMBASA s.n. ALCB: 57915 (4), 60952, 60956 (3); Equipe Morg. s.n. RFA 5003 (2); Freitas, J.S. s.n. HUNEB 12843 (5); Guerra, M.A.O.F. s.n. ALCB 107130 (7), RFA 1706 (7); Kanagawa A.I. s.n. JPB 11380 (7); Lúcio A.M. s.n. ALCB 49155 (5); Marques, R.J. s.n. ALCB 17459 (5); Mitchell, G.J.P. s.n. ALCB: 107124-107126, 107131 (7), RFA: 927 (1), 2041, 4453, 4496, 4598 (7), 7224 (1); Nassar, C.A.G. s.n. ALCB 107128 (7), RFA 4363 (7); Nunes, A.P.M. s.n. HUNEB 2022 (1); Nunes, J.M.C. s.n. ALCB: 22271 (1), 48447 (5), 48451 (1), 52964 (7), 57460 (1), 68409 (5), 73421 (6), 73429 (5), 73465 (6), 103535, 103538 (1), 103711 (7), 103712 (6), 103726 (5), 118452(1) HUNEB: 8377 (1), 10106,13042 (5); Nonato, E. s.n. SPF: 639 (1), 4426 (5); Oliveira, E.C. s.n. SPF 51158 (2); Projeto Revizee s.n. RFA: 28545 (3), 28547,28681 (2), 28683 (4), 28682, 28685, 28686 (3), 28691, 28696, 28697, 28810,28811 (2), 28813 (4), 28814 (3); Ramos, M.E.C. s.n. ALCB: 53197 (5), 53395 (1) 53433, 86442 (6); Santos, A.C.C. s.n. ALCB 17471 (5); Santos, G.N. s.n. ALCB: 103400, 103401 (1), 103480, 103498 (5), 103519 (1), 103551 (5), 103691 (1), 103713 (6), 103716, 103724, 103890, 106970 (5), 109498 (1), 109557 (5), HUNEB: 12721 (1); Santos, J.P.P. s.n. SPF 29717 (1): Silva, B.N.T. s.n. SPF 56789 (6): Turma de Ficologia 95.1 s.n. HUNEB 11158 (2): Ugadim, Y. s.n. SPF: 28354 (1), 29736 (5). 